\title{
Carbon Cycling In Northern Peatlands
}

\author{
Andrew J. Baird, Lisa R. Belyea, Xavier Comas, \\ A.S. Reeve and Lee D. Slater (editors) (2009)
}

AGU Geophysical Monograph Series, Volume 184 American Geophysical Union, Washington DC, USA

\author{
299 Pages \\ Hardbound
}

Price: US\$136.00 (AGU member: US\$ 95.00)

ISBN: 978-0-87590-449-8

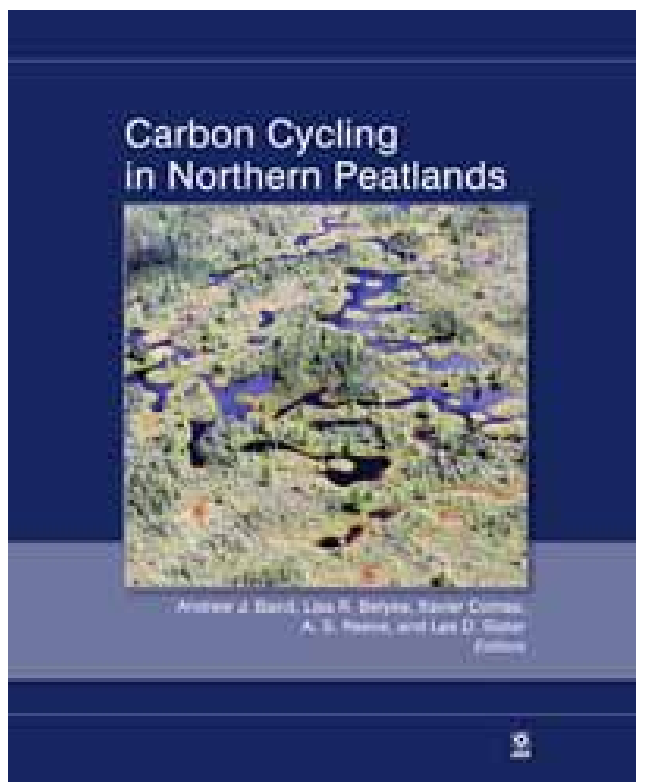

Scientific papers on peatland ecosystems frequently start with a statement about peatlands covering only $2 \%$ of the land surface, but containing approximately $30 \%$ of the global terrestrial carbon pool (most often citing Gorham 1991). Together with the substantial emission of methane from peatlands to the atmosphere, these characteristics raise important questions about the past, current and future role of peatlands in the global carbon cycle. A particularly pressing issue is to what extent peatland-atmosphere carbon fluxes will be affected by global climate change. With their book 'Carbon cycling in Northern Peatlands', the editors aim to: 1) Highlight that contrary to the emphasis in the older literature of peatlands being archives of climate change, peatland ecosystem properties actively respond to climate change, possibly feeding back to changes in the climate system and 2) Present an overview of the state of the art in various disciplines involved in the research on peatland carbon cycling. This overview should be accessible to a wide audience (including e.g. climate modellers). The focus on northern peatlands (higher than $45^{\circ} \mathrm{N}$ ) is motivated by their significance in terms of areal extent and their importance as carbon stores, and that the strongest climatic changes are predicted to occur in these latitudes during the coming century. More than forty authors have contributed to the book's twenty-one research papers, which are divided into four different sections. (The complete table of contents can be found on the publisher's website: http://www.agu.org/cgi-bin/agubooks?toc= ASGM1844498\&book=ASGM1844498\&topic $=\&$ se arch)

The first section focuses on large-scale peatland carbon dynamics and carbon cycling. It is argued that peatland dynamics are non-linear, suggesting that gradual changes in climate could lead to relatively rapid and unexpected changes in peatlandatmosphere carbon fluxes. Such flux changes could feed back to changes in the climate system. Until now, peatlands have not yet been implemented as a land cover type in the climate system models (also referred to as Global Circulation Models, GCMs). The section highlights a number of challenges for incorporating peatlands in GCMs: 1) Peatlands have a number of unique features that separate them from other land cover types. These features will make it difficult to incorporate peatlands in GCMs in a way that is consistent with the level of detail that is used for other land cover types. 2) Model predictions lead to considerable error when small-scale $(1-10 \mathrm{~m})$ processes within peatlands are ignored. However, consideration of these small-scale processes in large-scale (global) models is computationally difficult, if not impossible. 3) There are considerable differences in peatland initiation and carbon accumulation rates among regions due to climatic variation and due to different degrees of seasonal variation. 4) In some areas, human activity (especially agriculture) exerts a strong influence on peatland-atmosphere carbon fluxes. Throughout the section, a number of approaches are proposed that could deal with some of the challenges outlined.

The second section considers processes that occur near the peatland surface layer. Particular attention is paid to decomposition and plant production processes. The latter type of processes may be quantified by means of remote sensing techniques. Remote sensing techniques are most commonly used for land cover mapping, but a review of recent advances suggests increased 
possibilities to develop algorithms that translate remote sensing data into physiological attributes of peatland vegetation (such as Gross Primary Productivity and Leaf Area Index). The remainder of Section Two focuses on decomposition. An overview is given of the different microbial decomposition pathways and how microbial community structure, and hence the importance of the different pathways, changes with environmental conditions and along the peat profile. Another chapter shows that considerable variation is observed in the partitioning of decomposed peat into carbon dioxide and methane. This variation cannot be fully explained by models of aerobic and anaerobic decomposition. Therefore, more research is needed that uses a similar methodology and a stronger link between laboratory and field experiments. Finally, decomposition not only involves carbon emission, but also mass loss from the peat layer and release of nutrients that may become available for plant uptake. A meta-analysis and a detailed case study suggest that vegetation type (vascular plants or Sphagnum) is a more important determinant of decomposition and nutrient release rates than climatic variables. This suggests that the most important effect of climate change on peatland decomposition may be indirect, by altering the competitive balance between vegetation types.

Section Three is about methane accumulation in and emission from northern peatlands. Recent research suggests that episodic releases of methane bubbles (ebullition) may be more important than previously thought. One chapter discusses and models in detail how environmental factors (notably air pressure, water table height and temperature) could control ebullition episodes. An interesting issue that emerges is where in the peat profile most methane bubbles are formed. Measurements in the Glacial Lake Agassiz complex in North America suggest bubbles are mainly formed in deep peat. This notion is also supported by novel techniques such as Ground Penetrating Radar (GPR), which revealed that gas bubbles might be trapped by a confining layer in deep peat until released. Another chapter, however, suggests that rates of methane bubble formation may be at least as high in the upper $1 \mathrm{~m}$ of the peat profile. A model for bubble transport is proposed, revealing that even under a constant rate of methane formation, episodic ebullition from the shallow peat layer could occur. Both methane and carbon dioxide emissions from shallow peats can be studied in detail in laboratory studies using mesocosms. One chapter discusses in detail the experimental setup and possible output of these studies. Another chapter examines to what extent carbon isotope signatures of emitted methane can be used to derive the sources and processes leading to its production.

The fourth section focuses on hydrological transport processes and associated export of Dissolved Organic Carbon (DOC) from peatlands. A review of evidence from North American peatlands suggests that DOC is a significant part of the carbon cycle, calling for integration of DOC into models of peatland carbon cycling. A review of a long-term dataset of DOC export from British catchments suggests that DOC export is controlled by both general and regional (catchment-specific) factors, and especially that solubility of DOC (rather than its production) is an important control on export rates. Another chapter shows how water transport within and from peatlands is affected by the formation of natural soil pipes. Data suggests that water flow through such pipes may contribute up to half of the DOC transport from peatlands, and also that Particulate Organic Carbon (POC) may be exported through pipes during storm events. Another chapter shows how hydrological flow patterns may be altered by permeable lenses in the mineral subsoil. Cross-sectional models that are calibrated with field data reveal how permeable lenses can create anomalies in vertical flow patterns within peatlands, which are often ascribed to biogenic gas formation (such as methane bubbles). The importance of the hydrogeological setting of peatlands for carbon cycling processes is also stressed in another chapter. Finally, it is also discussed how the hydrological system is altered through peat cutting. One of the conclusions is that peatland restoration should also include restoring the hydrological system. It is argued that establishment of peat mosses (Sphagnum) is a key component to restore the hydrological system.

While reading the book I observed the following cross-cutting themes through the different sections. Particular challenges for quantifying the carbon cycling processes in northern peatlands are the multiple levels of spatial and temporal heterogeneity involved. Spatial heterogeneity occurs through small-scale alternation of hummocks and hollows, which function fundamentally differently in peatland carbon dynamics. Also, heterogeneity in the vertical direction is important: confining layers may trap methane bubbles, whereas permeable lenses in the mineral subsoil may alter water flow patterns. Ignoring these spatial heterogeneities may lead to considerable error when quantifying biogeochemical (transport) processes in peatlands. Another aspect of spatial heterogeneity is that there are important site-specific controls on carbon cycling, which hampers identification of trends and 
upscaling of results. Also apparent is the temporal heterogeneity in carbon fluxes, especially the episodic nature of methane emissions, but also of DOC and POC export. Further, seasonal variation is an important control on carbon dynamics. To meet these challenges, several chapters emphasise the strong need for standardised methodologies that enable comparisons between results (e.g. methane emission, nutrient release rates, effect of human land use) of different study sites. Finally, a cross-cutting theme seems to be the potential to combat some of the current challenges with improved or novel methods (e.g. GPR, remote sensing, reduced complexity models).

Most papers have a somewhat different character than standard journal papers, which works well for the book. Many chapters provide a useful state of the art of a specific subject but also provide new or modified conceptual frameworks and models. There is also room for elaborate descriptions of specific methods and techniques, and proposition of new models that are in the first stages of development. I think that the combination of reviews and new ideas will make this book appealing for people seeking an introductory text on peatlands, but also for peatland scientists interested in an update of their field.

The chapters are all written as stand-alone papers. Hence, an important advantage is that readers can easily read a subset of chapters without missing essential information. Considering that the book is targeted at a wide audience, it is indeed likely that people will be interested in specific parts of the book. This format, however, also leads to overlap between the chapters. For example, the main differences between aerobic and anaerobic decomposition are explained in at least nine chapters. In my view, a useful way to deal with such overlap is to use cross-references to the chapter that explains the subject in most detail. Crossreferencing frequently occurs in the first two sections of the book, but not in the third and fourth sections.

Although the book covers a wide range of subjects, I would have liked to read a chapter specifically on the (projected) effects of permafrost thawing on peatland carbon cycling. Also, I would have liked a closing chapter of the book to summarise cross-cutting themes (e.g. like the ones I noticed above, or maybe others), take-home messages, and the priorities for future research. Such a closing chapter could have highlighted the synergistic value of presenting a set of research papers in one volume.

The book has been well edited. The figures are clear and of high quality, and there are very few typos in the text (it is my impression that slightly more errors occur in figure legends). I am only a bit puzzled about the limited number of entries listed in the index: it only contains 26 entries, mostly rather general terms.

These are obviously only minor comments. In my view this book provides a good overview of the state of the art and future challenges in peatland carbon cycling research. Also, the notion that peatlands are an interactive component of the climate system (rather than being only archives of climate change) strongly resonates throughout the book. Hence, the goals set out by the editors are, in my opinion, indeed reached by this book. The book is probably accessible to a wide audience. For a few chapters some specific background (in mathematics, chemistry or microbial taxonomy) may be helpful, but is not essential to grasp the main points. I would recommend this book to graduate students and more advanced scholars who would like to learn more about carbon cycling in northern peatlands. On the other hand, I think this book also provides a very useful update to any scholar who relies on 'peatlands contain $2 \%$ of the land surface, yet contain $30 \%$ of the global carbon pool' when presenting her/his work.

\section{REFERENCES}

Gorham, E. (1991) Northern peatlands: Role in the carbon cycle and probable responses to climatic warming. Ecological Applications, 1, 182-195. 